\title{
Spominska krajina in dediščina prve svetovne vojne v Julijskih Alpah
}

JAKA REPIČ

Prva svetovna vojna je bila v mnogih pogledih pomembna zgodovinska prelomnica in kot taka tudi globoko formativna tako za evropsko kot globalno družbo. Kljub trajnim družbenim posledicam vojne in povojnih procesov vzpostavljanja spomina, dediščine in krajinskih sprememb pa so raziskovalci prvo svetovno vojno preučevali večinoma $\mathrm{z}$ vidika zgodovine, vojaških taktik in političnih ved. Eden vodilnih avtorjev na področju raziskav vojne krajine in procesov tvorjenja dediščine prve svetovne vojne v alpskem okolju, Nicholas Saunders, $\mathrm{v}$ več delih opozarja, da zgodovinske raziskave prve svetovne vojne kraj in krajino navadno razumejo kot prazno ozadje vojaškemu dogajanju in posledičnim politikam ter praksam oblikovanja spomina in vojne dediščine. Krajino razumejo kot neposlikano platno, ki ga 
opredeljujejo šele človeške dejavnosti, ne pa kot dvosmerni proces integracije človeških dejavnosti v krajino in okoljskih značilnosti v prostorske percepcije in izkušnje. Antropologija se je s prvo svetovno vojno začela ukvarjati šele nedavno, čeprav ravno antropološka perspektiva, kot pravi Saunders, odgovarja na nekatera zelo relevantna vprašanja:

\begin{abstract}
Prva svetovna vojna ostaja dvoumno »nedavna « v podobah med ljudmi v Evropi - lebdi na meji med »živo « ustno zgodovino, vojaško zgodovino, muzeologijo ter vprašanji turizma in kulturne dediščine. /.../ Antropološko utemeljene raziskave ponujajo vsaj priložnost za obravnave: a) konflikta, ki je bil doslej znan predvsem iz zgodovinskih virov; b) rekonstrukcije (po)vojnih krajin; in c) razvoja komemorativnih materialnosti, tako velikih kot malih (od velikih spomenikov do majhnih osebnih spominkov). (Saunders 2013: 20)
\end{abstract}

Prispevek je rezultat raziskave o spominski krajini in vojni dediščini znotraj raziskovalnega projekta Dediščina prve svetovne vojne: reprezentacije in reinterpretacije (glej Jezernik in Fikfak 2018), zgodovinsko in etnografsko preučuje vzpostavljanje spomina na prvo svetovno vojno in procese oblikovanja dediščine $\mathrm{v}$ alpski krajini v Sloveniji. Preučuje vplive prve svetovne vojne na krajinske spremembe v alpskem delu soške fronte in njenega zaledja, predvsem v bohinjski dolini, ter povojne obnove krajine do sedanjosti. Obravnava spominsko krajino, ki je nastala kot vojna krajina in je bila po vojni podvržena dodatnim spremembam povojne obnove, zapuščanja in propadanja vojaških objektov ali postavljanja pokopališč, spomenikov, kapelic, tematskih poti, muzejev. Na to spominsko krajino so vezane sodobne komemorativne prakse, reprezentacije vojne ter tvorjenja (re)interpretacije socialnega spomina in dediščine.

Teoretsko razprava izhaja iz sodobne arheološke, geografske in zlasti antropološke literature o krajini in okolju, ki opozarja na nenehno spremenljivost okolja, pri tem pa ne ločuje med človeški$\mathrm{mi}$ in drugimi naravnimi procesi. $\mathrm{V}$ tem smislu je (po)vojna krajina način spominjanja in tvorjenja dediščine, pa tudi sredstvo oblikovanja identitete in lokalnosti. Krajino pojmujem kot podlago za niz raznovrstnih okoljskih praks in materialnosti, na primer postavljanja spomenikov ter vzpostavljanja komemorativnih in dediščinskih praks, ki omogočajo sodobne reinterpretacije prve svetovne vojne. Povezave med krajino, spominom in identitetami se po eni strani vzpostavljajo skozi komemoracije in tvorjenje dediščine, na drugi pa skozi percepcije okolja in prostorske izkušnje različnih akterjev, prebivalcev, obiskovalcev. 
Prispevek je razdeljen na tri glavne dele: začne se s predstavitvijo antropoloških raziskovalnih pristopov in teoretskih razprav o krajini in okolju, temu pa sledi predstavitev koncepta vojne in spominske krajine ter nekaterih primerov oblikovanja spominske krajine po prvi svetovni vojni. V naslednjem delu prispevek predstavi krajinske spremembe, ki so posledica vojaške tehnologije in bojevanja na soški fronti in v njenem zaledju, zlasti v bohinjski regiji. Med okoljskimi spremembami obravnavam topografske, morfološke in infrastrukturne spremembe, ki so nastale kot neposredna posledica vojaške tehnologije in bojevanja na fronti: nove železniške proge, gorske poti, žičnice, vojaške stavbe, izsekavanje gozdov; pozneje so postale temelj vzpostavitve spominskih krajev, komemorativnih praks kot tudi lokalne in nacionalne dediščine. Okoljske spremembe poleg fizičnih zajemajo tudi spremembe $\mathrm{v}$ socialni, ekonomski in politični krajini, na primer nove industrije in gibanje prebivalstva: mnogi domačini so bili vpoklicani v vojsko in so se večinoma borili na oddaljenih frontah, v Bohinj pa je prišlo na tisoče vojakov avstro-ogrske vojske in vojnih zapornikov. V zadnjem delu pa obravnavam spominsko krajino skozi komemorativne prakse ter primere tvorjenja vojne in povojne dediščine $\mathrm{v}$ bohinjski regiji kot tudi širše $\mathrm{v}$ alpskem zaledju soške fronte. Po vojni so vojaškim stavbam in predmetom prebivalci regije in obiskovalci spremenili namembnost, utrdbe in kaverne so prepustili preraščanju in pozabi ali pa so jih spremenili v kraje spomina in dediščine. Uredili so pokopališča in spomenike, ki so postali kraji spominskega in pietetnega turizma, zlasti $v$ zadnjem času pa tudi institucionalnega oblikovanja (po)vojne dediščine.

\section{RAZISKAVE KRAJINE IN OKOLJA V ANTROPOLOGIJI}

Krajina je že dolgo uveljavljen koncept $\mathrm{v}$ antropologiji, arheologiji in geografiji, izhaja pa iz zanimanja, kako smo povezani ljudje in okolje. Christopher Tilley opaža, da so raziskovalci v preteklosti koncept krajine ter odnos med ljudmi in okoljem razumeli večinoma $\mathrm{v}$ smislu funkcionalnih in prilagoditvenih parametrov ali geografske determiniranosti, na primer zaradi okoljskih omejitev ali kot najvišje demografske ravni glede na obstoječe načine materialne produkcije med nekim prebivalstvom. Tak naturalistični oziroma ekološki pristop krajino razume kot ozadje človeškim dejavnostim in sredstvo materialne produkcije. Človek je sicer odvisen od okolja, a ga razume kot pasivni del družbenega sveta. 
Sodobne razprave v antropologiji, geografiji in arheologiji krajino največkrat obravnavajo skozi dva glavna pristopa. Prvi, fenomenološki skuša pojasniti, kako ljudje doživljajo okolje oziroma kakšni sta njihovi zaznava in izkušnja okolja. Strukturni pristopi pa skušajo pojasniti, » kako krajino in okolje krojijo politični, družbeni, ekonomski in zgodovinski dejavniki « (Árnason 2010: 80). Strukturni pristopi se torej osredotočajo na politične, družbene, kulturne in ekonomske dejavnike, ki skozi zgodovinske procese spreminjajo in preoblikujejo krajino, vendar ne pojasnjujejo, kako ti dejavniki vplivajo na prostorske izkušnje ljudi, ki bivajo v nekem okolju ali se gibljejo skozenj. Fenomenološki pristopi, ki so jim izhodišče neposredne izkušnje okolja, pa se ukvarjajo prav s slednjim (npr. Ingold 1993; Tilley 1994; cf. Ingold in Vergunst 2008). Zanimajo jih načini, na katere ljudje zaznavajo svet, ga doživljajo in si ga razlagajo, pri čemer fizično in družbeno okolje tvorita isti svet, $\mathrm{v}$ katerem ljudje bivamo.

Med pomembnejšimi avtorji, ki so pisali o krajini, naj najprej omenim Denisa Cosgrova in Stephena Danielsa, ki sta v delu Ikonografija krajine (The Iconography of Landscape) opozorila, da je krajina ideološki koncept oziroma kulturna reprezentacija okolja (Cosgrove in Daniels 1988; glej tudi Cosgrove 1984). To utemeljujeta že z zgodnjo uporabo angleške besede krajina (landscape), ki je sprva označevala likovni žanr in krajinske likovne podobe okolja v tihožitju, kot ga vidi slikar in pozneje nekdo, ki opazuje sliko. »Krajina je kulturna podoba, likovni način reprezentacije, strukturiranja in simboliziranja okolja « (Daniels in Cosgrove 1988: 1). Po njunem mnenju je krajina zgolj literarna, umetnostna ali politična reprezentacija okolja: »Ideja krajine označuje umetnostne in literarne reprezentacije vidnega sveta, to je kulise, kot jo vidi gledalec « (Cosgrove 1984: 9). Tudi Tim Cresswell zagovarja podobno stališče, ko zapiše: »Mi ne živimo v krajini, ampak jo gledamo « (2004: 11). Krajina naj bi bila torej način gledanja, kulturna podoba ter njene umetnostne, literarne in materialne reprezentacije dejanskega okolja. Tako kot naj bi bila ločena notranji in zunanji svet, je človek ločen od okolja; tega le opazuje ter si ga razlaga. Reprezentacije krajine so torej podvržene nenehnim interpretacijam in imajo, kot pravi Christopher Tilley, moč, da zameglijo ali artikulirajo prostorske izkušnje (1994: 25). Tudi krajinske reprezentacije spominov in dediščine so kompleksne in pogosto sporne, saj so nenehno podvržene političnim reinterpretacijam.

Takšnemu razumevanju koncepta krajine, ki temelji na ločenosti med zunanjim dejanskim svetom ter notranjim (kulturnim, psihološkim) zaznavanjem in razumevanjem tega sveta, so nasprotovali avtorji, ki so na splošno izpodbijali inherentno ločenost med »notranjim in 
zunanjim svetom, med umom in materialnim, pomenom in stvarjo « (Ingold 1993: 156; prim. Lund in Benediktsson 2010). Tim Ingold se namesto tega osredotoči na perspektivo bivanja v okolju:

Krajina je svet, kot je poznan tistim, ki v njem bivajo, ki naseljujejo njegove kraje in potujejo po poteh, ki te kraje povezujejo (Ingold 1993: 156).

Tudi Tilley je zavrnil idejo krajine kot zgolj mentalnega spoznavanja in reprezentacije. Opozoril je na dvosmernost materialnega sveta in percepcije okolja, pa tudi na to, da smo ljudje prav tako del okolja:

Lokacije v krajini so lahko naravne danosti, kot so obalni zalivi, hribi ali pa človeško ustvarjeni kraji, kot so spomeniki ali naselja (Tilley 1994: 25).

Krajine namreč s perspektive človeške izkušnje ne moremo deliti na naravno in umetno, saj oboje tvori okolje, v katerem ljudje bivamo. Poleg tega je krajina močno spremenljiva, zato je treba razumeti tudi njeno časovno razsežnost (prim. Bender 1993; 2001a; 2001b; 2002; Tilley 1994: 2012; Hirsch 1995; Massey 2006). Krajino namreč zaznamujejo morfološke, arheološke in konceptualne spremembe, ki jih Ingold opiše kot »vzorec dejavnosti, strnjenih v nizu krajinskih značilnosti « (1993: 166).V tem smislu si krajine ne moremo razlagati kot plasti ostankov zgodovinskih dogodkov, ampak kot okolje, ki je vselej neposredno povezano z družbeno realnostjo. Pretekle in sedanje človeške dejavnosti niso le vtisnjene $v$ krajino, ampak so del nje: »Krajine so del sveta gibanja, odnosov, spominov in zgodovin « (Bender 2001b: 76; prim. Feld in Basso 1996; Bender in Winer 2001). Izkušnje sedanjih prebivalcev so torej vselej utemeljene $\mathrm{v}$ zgodovinsko oblikovanem in spreminjajočem se okolju. Ingold zagovarja, da so ljudje in okolje vzajemno konstitutivni dejavnik sprememb istega sveta, ki ni ločen na notranjega in zunanjega:

\footnotetext{
... krajina ni nikoli končana: niti ni zgrajena niti nezgrajena, temveč je vedno v nastajanju. /.../ Krajinske oblike niso prednarejene za življenje ljudi - niti v smislu naravno oblikovanih niti v smislu narejenih od človeških rok -, kajti prav sam proces bivanja je tisti, skozi katerega so te oblike ustvarjene. (Ingold 1993: 162)
}

Sodobni svet so izjemno močno oblikovale tudi vojne in vojaška tehnologija, z okoljskimi spremembami in procesi, ki so jih prinesle vojne, pa so ljudje živeli naprej tudi po koncu vojn. Dejavnosti in dogodki med samo vojno, povojne obnove, propad stavb in vzpostavljanje spominskih krajev so del spominske krajine, ki v 
sodobnem času omogoča reinterpretacijo vojne kot tudi vzpostavljanje praks in dediščine.

\section{RAZISKAVE (PO)VOJNE IN SPOMINSKE KRAJINE}

Prva svetovna vojna in formalizacija spominov nanjo sta imeli pomemben vpliv na oblikovanje evropskih družb, politik tvorjenja dediščin in komemorativnih praks (Saunders 2001a). Saunders vojne krajine, še posebej zahodno fronto, označuje za simbolno krajino sodobnega časa: »človeške izkušnje krajin zahodne fronte med letoma 1914 in 1918 so bile globoko formativne ... in so vtisnile žive podobe $\mathrm{v}$ individualne in kolektivne spomine « (Saunders 2001a: 37).

Vojne in vojaške krajine so družbeno in zgodovinsko konstruirane krajine, ki jih sestavljajo fizični kraji z množico materialnosti, kot so naravne danosti, zgradbe, poti, ceste, infrastruktura, spomeniki, spominski kraji in kraji komemorativnih dogodkov. Vojaške dejavnosti so bile vključene $\mathrm{v}$ krajino, prav tako pa so krajinske značilnosti zaznamovale prakse in izkušnje bojevanja. To je opazno na alpski fronti prve svetovne vojne, kjer se je razvilo statično gorsko bojevanje, to pa je spremenilo samo okolje in močno zaznamovalo tudi izkušnje vojakov, ki so se borili v tem okolju (prim. Keller 2009). Spominjanje prve svetovne vojne je trajni proces prostorskega vključevanja vojnih in vojaških dejavnosti v krajino ter oblikovanje spominskih in dediščinskih praks, v katere se vključujejo različni lokalni, nacionalni ali mednarodni akterji kot tudi institucije.

Rachel Woodward je zelo široko opredelila vojne krajine kot »krajine, ki v svoji obliki in izraznosti odsevajo odtis vojaških dejavnosti « (2014: 41). Glede na razprave, ki so opozorile na trajno vzajemno konstitutivnost človeka in okolja, lahko opredelitev vojne in povojne spominske krajine razširimo na krajine, ki zajemajo niz vojaških in vsakdanjih dejavnosti in materialnosti, pa tudi povojno obnovo, vojne ostanke in spomenike ter komemorativne in dediščinske prakse. Vojni spomeniki, arhitekturni in tehnološki ostanki, prostorske prakse, politika memorializacije spreminjajo zaznavanje krajine in njene podobe, $s$ tem pa tudi lokalne in nacionalne zgodovine ter dediščine. Takšno vojno spominsko krajino predstavlja tudi območje soške fronte $\mathrm{z}$ geografskim zaledjem, $\mathrm{v}$ katerem so vojni ostanki, pokopališča, oskrbovalne poti, utrdbe, spomeniki in neštete pripovedi o bitkah, človeškem trpljenju in dosežkih.

Koncept vojne (oziroma vojaške) krajine v antropologiji ni prav pogost, precej bolj se pojavlja v vojaških študijah ter zgodovinskih, 
geografskih in deloma v arheoloških raziskavah. Vojaške študije so, na primer, koncept krajine uporabljale predvsem $\mathrm{v}$ smislu izrabe okolja in prilagajanja vojaških strategij. Tudi vojne fronte in bojišča, ki so vojna krajina per se, je največ raziskovala vojaška zgodovina, in sicer kot $\gg$ kraj propada, človeške bede, trpljenja, smrti in morebitne zmage « (Saunders 2001a: 37). Zato tudi prevladujejo raziskave, ki vojno krajino razumejo kot pasivno, prazno ozadje, $\mathrm{v}$ katerem prihaja do vojaških akcij.

Rachel Woodward (2014) pa vseeno našteje nekaj del, ki krajino prve svetovne vojne obravnavajo tudi v smislu oblikovanja identitete, socialnih spominov in vzpostavljanja dediščine. Ross Wilson (2011), na primer, obravnava, kako so britanski vojaki na zahodni fronti poimenovali kraje in krajinske značilnosti, kar je omogočalo vzpostavljanje občutka poznanih krajev in oblikovanje vojaške identitete. Po vojni so mnogi takšni kraji postali pomembni za komemoracije, turizem in vzpostavljanje vojne dediščine (glej npr. Morris 1997; Iles 2003; Winter 1998 [1995]; 2006; Saunders 2001b; 2002). David W. Lloyd (1998) opiše razvoj povojnega turizma in romarskih obiskov spominskih krajev, spomenikov, pokopališč, krajev, kjer je prihajalo do bitk, kot tudi vpliv spomenikov in spominskega turizma v interpretaciji spomina na vojno v Veliki Britaniji, Kanadi, Avstraliji. Delo pokaže, kako so se nekateri spomeniki spremenili v romarske kraje, odnos do spomina na vojno pa se je spreminjal ves čas po vojni. Jennifer Iles prav tako opiše razvoj spominskega turizma na lokacije zahodne fronte med nekdanjimi britanskimi vojaki ali njihovimi sorodniki. Snezhana Dimitrova (2005) obravnava različne komemorativne prakse, spominska obeležja in spomenike bolgarskim vojakom prve svetovne vojne kot krajino spomina in pozabe, ki je imela tudi pomembno vlogo v oblikovanju nacionalne identitete.

Saunders je predlagal obravnavo front prve svetovne vojne ne samo kot »niz bojnih polj, temveč kot sklop prekrivajočih se večglasnih krajin « (Saunders 2001a: 37). V teh »večglasnih « krajinah namreč ne prevladuje le vojaški del zgodovine, ampak se vanje vključujejo različni lokalni in nacionalni akterji ter institucije, ki skušajo obvladovati interpretacije vojne kot tudi vzpostavljanje dediščine na lokalni ali nacionalni ravni. Tako tudi človeške dejavnosti niso vpete $\mathrm{v}$ krajino le kot zgodovinske plasti, ki jih arheološko razkrivamo, temveč so vključene v krajino, ki je nenehno podvržena spremembam, reprezentacijam in reinterpretacijam. Tudi ta prispevek vojno krajino soške fronte in njenega zaledja razume kot še vedno trajajoč proces, ki tudi stoletje po koncu vojne še vedno vpliva na življenja, spomine, politiko in procese vzpostavljanja dediščine. 
Med prvo svetovno vojno je bila bohinjska dolina pomembno oskrbovalno zaledje za nekatere gorske dele soške fronte. $\mathrm{Ob}$ začetku vojne je na območju Bohinja v manjših vaseh ter glavnem administrativnem in industrijskem kraju Bohinjska Bistrica živelo manj kot pet tisoč prebivalcev. Zgodovinsko so gospodarske dejavnosti doline večinoma temeljile na gozdarstvu, izkopu železove rude in kmetijstvu. V kmetijstvu so prevladovali govedoreja s transhumantnim pašništvom, sirarstvo in mlekarstvo, razvito je bilo tudi usnjarstvo (glej Repič 2014). Zaradi pašništva $\mathrm{v}$ dolini in na okoliških planinah, gozdarstva in lova je bilo gorsko okolje ob začetku vojne že prepredeno s potmi, na planinah so že dolgo poznali tudi naselbine, ki so jih uporabljali le sezonsko. Arheološke raziskave bohinjskih planin sicer kažejo, da so najzgodnejše naselbine nastale že med sedmim in tretjim stoletjem pred našim štetjem. Vsaj v srednjem veku pa je prebivalstvo razvilo poletno transhumantno pašništvo na več višinah na okoliških planinah, ki so večinoma oddaljene več ur hoda od naselbin v dolini. Pred vojno so bile človeške dejavnosti torej že popolnoma vključene v gorsko okolje, kot se na primer vidi v višje ležečih planinah, ki so se razvile prav zaradi krčenja gozda, pašništva in visokogorskega poletnega sirarstva (prim. Repič 2014).

$\mathrm{Z}$ devetnajstim stoletjem se je $\mathrm{v}$ Bohinju začel razvijati gorski turizem, z njim pa tudi infrastruktura in storitve, na primer gorske poti in organizirano vodenje, ki je uporabljalo obstoječe krajinske značilnosti, a je krajino tudi spreminjalo. Tatiana Bajuk Senčar, na primer, piše, da so gorski vodniki odkrili obstoječe lovske in druge poti ali zgradili nove poti in gorske koče (Bajuk Senčar 2005: 76). Vse od poznega devetnajstega stoletja se je v Bohinju močno razvijal prav turizem, ki je še zdaj ena glavnih gospodarskih dejavnosti. Turistični razvoj se je sicer ustavil med prvo svetovno vojno, a se je nadaljeval po vojni, tudi z novimi oblikami spominskega turizma.

Prva svetovna vojna je $\mathrm{v}$ Bohinju in širšem zaledju soške fronte pustila trajen pečat $\mathrm{v}$ družbi, gospodarstvu in krajini. Vojaška fronta je bila nad Bohinjem vzpostavljena spomladi 1915, že prej pa je začelo prihajati do pomembnih sprememb. Mnogi, ki niso bili zaposleni na izgradnji vojaške infrastrukture, so bili vpoklicani v avstro-ogrsko vojsko. V juliju 1914, ko se je začela mobilizacija, je bilo zgolj iz Bohinja na vzhodno fronto poslanih približno dvesto moških.

Ko je 23. maja 1915 Italija napovedala vojno Avstro-Ogrski, se je oblikovala približno šeststo kilometrov dolga avstrijsko-italijanska fronta, ki se je raztezala od prelaza Stelvio v bližini tromeje med Italijo, 
Avstrijo in Švico prek Trentina, Južne Tirolske, Dolomitov, Karnijskih in Julijskih Alp ter po dolini reke Soče do Jadranskega morja. Del te fronte je bila soška fronta, ki je nastala junija 1915 z italijansko ofenzivo, s katero je italijanska vojska neuspešno skušala zavzeti dolino Soče ter prečiti kraško planoto in gorski greben. Fronta se je raztezala med goro Rombon na severu, ki je znana po izkopanih jarkih in predorih, in izlivom reke Soče v morje. Tudi zaradi zahtevnega gorskega terena je bila italijanska vojska neuspešna proti obrambi sprva manj številčne avstro-ogrske vojske. Obe strani sta se nazadnje vkopali na položaje za več kot dve leti. Šele oktobra 1917 sta avstro-ogrska in nemška vojska med dvanajsto bitko soške fronte oziroma bitke pri Kobaridu uspeli prebiti italijansko obrambo in njeno vojsko potisniti v nižavje Benečije vse do reke Piave.

Glavna značilnost zahodne in alpske fronte, tudi soške, je bilo statično bojevanje. Soška fronta je bila skoraj dve leti in pol utrjena, velik del celo v visokogorskem okolju, ki je na obeh straneh omogočalo dobre obrambne položaje. Vojaki so bili sicer zaščiteni v utrdbah in kavernah, a so vojno doživljali skozi bivanje in bojevanje $\mathrm{v}$ gorskem okolju. Kljub statičnemu bojevanju je vojna zgolj na območju soške fronte zahtevala izjemno veliko število žrtev, z ocenami, ki segajo med sedemsto tisoč in milijonom.

Fronte so bile vojaško organizirane na samo bojno fronto in njeno zaledje, ki je bilo prav tako močno vpeto v vojaško dogajanje. Bohinj je predstavljal pomembno zaledje za del soške fronte, zlasti za bojišče na Krnu v visokogorju nad dolino Soče. Posebej pomembno vlogo je imel pri vojaškem oskrbovanju visokogorskih bojišč, v zaledju je namreč bivalo veliko več ljudi kot na sami fronti. Poleg tega je vojska zaledje močno industrializirala in izgradila veliko vojaške infrastrukture, kot so poti, žičnice, ceste, železnice. Prisotnost vojske je popolnoma prevzelo vsakdanje življenje v Bohinju med vojno. Gibanje prebivalstva je bilo nadzorovano, pot $\mathrm{v}$ dolino oziroma ven iz nje je bila možna le $\mathrm{z}$ dovolilnico (Budkovič 1999: 139). Veliko prebivalcev je bilo vpoklicanih v vojsko, obenem je na tisoče tujih vojakov prišlo $\mathrm{v}$ dolino in na bojišča fronte. Večina se je naselila $v$ vojašnicah, nekateri oficirji so bivali $v$ hotelih in gostilnah, vojaki tudi v hišah lokalnih prebivalcev. Poleg njih je v Ukancu vojska organizirala veliko zaporniško taborišče, kjer je nastanila več tisoč vojnih ujetnikov, večinoma ruskih vojakov $\mathrm{z}$ vzhodne fronte, ki so jih pripeljali za delo na infrastrukturnih objektih (Budkovič 1999: 77).

Lokalni prebivalci so morali zagotavljati hrano in druge stvari za vojsko, tudi z obvezno oddajo živine in pridelkov, nekateri pa so bili pri njej zaposleni, na primer na ozkotirni dostavni tovorni železnici. Veliko je bilo tudi novih zaposlitev zaradi vojaških potreb, zlasti v gozdarstvu, rudarstvu in sirarstvu, prav tako $\mathrm{v}$ gostinstvu in 
drugih dejavnostih za vojake. Začetni kraj za oskrbo fronte je bila Bohinjska Bistrica, glavni oskrbni poti sta vodili mimo Bohinjskega jezera do Ukanca, nato čez hribovje Komne do bojišča na Krnu ter skozi predor med Bohinjsko Bistrico in Tolminom v dolini Soče, ki je bil sicer dokončan leta 1906 kot del železniške povezave med Prago in Trstom.

Bohinjska železnica je imela pri oskrbi avstro-ogrske vojske ključno vlogo, po železnici so potovali vlaki z vojaki ali so dobavljali vojaško opremo, obleke, orožje, hrano in gradbeni material. V Bohinjski Bistrici je vojska zato zgradila velika skladišča, ki so jih pozneje uporabili za lesno industrijo. Leta 1915 so zgradili ozkotirno železnico med Bohinjsko Bistrico in Ukancem (glej Budkovič 1999: 35-45). Tovor so po njej sprva prevažali s konjsko vleko, leta 1917 pa so na Savici postavili elektrarno in elektrificirali tovorno železnico. Od Ukanca so tovor - hrano, obleko, strelivo, pošto, sanitetni in gradbeni material - naprej na Komno dostavljali s konji po mulatjeri ali tovorno žičnico. Ta je iz Ukanca vodila na Komno in naprej vse prek Bogatina do Peskov, krnskega bojišča proti Tolminu.

Ukanc, ki je bil sicer pašno območje lokalne agrarne skupnosti v Stari Fužini, se je zaradi vojne preobrazil v močno vojaško postojanko in ujetniško taborišče ruskih vojnih ujetnikov, ki so delali na poteh, cestah ali so jih uporabili za kopanje strelskih jarkov v zaledju fronte. Pašnik se je s tem spremenil v vojašnico s skladišči in prostori za ujetnike ter vsakodnevna opravila vojakov, tudi tistih, ki so se vračali s fronte. $\mathrm{Na}$ Komni na okoli 1500 metrov nadmorske višine, torej popolnoma v visokogorju, je avstrijska vojska postavila še eno vojaško postojanko z zgradbami za vojake in oficirje, menzo, skladišči, kapelo ter pokopališčem. Še ena manjša vojaška postojanka je ležala prav pred Bogatinskim sedlom na nadmorski višini skoraj 2000 metrov. Tu je bila tudi rezervna fronta z utrdbami za primer umika s krnskega bojišča.

Čez Komno je vodil tudi sistem tovornih žičnic, ki so ga postavili za oskrbo fronte. Najdaljša je vodila iz Ukanca do Komne, nato prek Bogatinskega sedla do Peskov in Tolmina (opis sistema žičnic glej v Budkovič 1999: 51-77). Vojska je poleg žičnic zgradila tudi vrsto gorskih poti oziroma mulatjer, vse z namenom utrjevanja in oskrbe fronte. Skupaj so na tem območju postavili več kot dvesto kilometrov žičnic, prepeljali pa so stotine ton opreme dnevno. Vse to so zgradili v gorskem okolju, v katerem je bilo pred vojno le malo infrastrukture, zgolj lovske in pašne poti, pašne planine ter zavetišča oziroma posamezne koče. Nova infrastruktura je temeljito spremenila gorsko krajino, ki je dobila poudarjen vojaški značaj. Po poteh so dnevno hodili vojaki in ujetniki, prenašali so orožje, hrano kot tudi trupla umrlih vojakov. 
Takšnih velikih infrastrukturnih projektov je bilo v zaledju fronte več. Tudi cesta iz Kranjske Gore na prelaz Vršič, naprej v dolino Trente vse do zgornje doline Soče, ki še danes predstavlja glavno povezavo med Zgornjesavsko dolino in dolino Soče, je bila zgrajena prav za oskrbo soške fronte. Cesto in žičnico na Vršič so gradili hitro, večinoma so na njej delali ruski, beloruski, ukrajinski, gruzijski in drugi vojaški ujetniki. Cesto je gradilo več kot deset tisoč ujetnikov. Med gradnjo v gorskem okolju so bili delavci izpostavljeni tudi težkim vremenskim razmeram. Tako jih je 8. marca 1916 presenetil velik snežni plaz, ki se je sprožil čez cesto in podrl tudi taborišče ujetnikov in stražarjev (Svoljšak 1997). V tem plazu je umrlo med dvesto in tristo ruskih vojnih ujetnikov ter okoli osemdeset avstrijskih stražarjev, kar še vedno predstavlja najbolj smrtonosen snežni plaz v Sloveniji. Še istega leta so ob cesti ruski ujetniki zgradili spominsko kapelo (Ruska kapelica), ki je bila leta 2006 prenovljena in je danes eden pomembnejših spominskih krajev, na katerem prirejajo komemorativne slovesnosti z močno politično konotacijo. Več sto ujetnikov je umrlo v plazu, še veliko več (ocene se gibljejo med osem in deset tisoč) pa jih je med delom na Vršiški cesti - leta 2006 preimenovani v Rusko cesto - umrlo zaradi težkih razmer, mraza, bolezni in izčrpanosti.

$\mathrm{V}$ nasprotju z zahodno fronto, ki je zasedla prej večinoma naseljeno okolje ali obdelovalne površine in spremenila idilično podeželsko krajino v puščavo »neskončnih kraterjev, bodeče žice (in) opustošenih zgradb « (Saunders 2001a: 38), je alpska fronta potekala tudi v večinoma nenaseljenem gorskem okolju, a so tehnološki, inženirski, arhitekturni in družbeni vplivi vojske in njene oskrbovalne verige krajini vseeno pustili močan pečat. Sama bojišča na frontah so bila vtisnjena v krajino z jarki, trdnjavami, kavernami, razstreljenimi tlemi, ostanki (tudi neeksplodiranega) streliva, ostanki vojaške opreme in celo človeškimi ostanki. Zaledje je bilo spremenjeno v industrijsko krajino oskrbovalnih cest, železnic, tovarn, vojašnic in zaporniških taborišč. Krajino bohinjske in drugih regij soške fronte ter njenega zaledja so sprva močno zaznamovale vojaške dejavnosti, utrdbe, množica vojaških pokopališč, pozneje pa povojna obnova ter rekonstrukcije v krajino spomina in dediščine.

\section{POVOJNA SPOMINSKA KRAJINA IN OBLIKOVANJE VOJNE DEDIŠČINE}

$\mathrm{Na}$ evropskih bojiščih je bilo ob koncu vojne leta 1918 družbeno in prostorsko opustošenje neprimerljivo s čimerkoli v zgodovini. Umrlih, pogrešanih in ranjenih je bilo na milijone, številni preživeli so bili bolni, 
pohabljeni ali duševno prizadeti. Območja bojišča so bila uničena, vojna pa je $\mathrm{z}$ industrializacijo in infrastrukturo spremenila tudi regije, oddaljene od samih bojišč. Blizu front so gradili ceste, železnice, elektrarne, gorske poti in tovorne žičnice, celotna območja so bila militarizirana. Drevesa so množično posekali in les uporabljali za gradnjo ali kurjavo. Krajina je zaradi vojaških dejavnosti in človeških izkušenj vojne dobila popolnoma nove pomene. V Alpah vojakov na fronti, ki so se varovali v kavernah, jarkih ali utrdbah, niso ogrožale le sovražne bombe, temveč so jih pozimi tudi surovo gorsko okolje, mraz in smrtonosni plazovi.

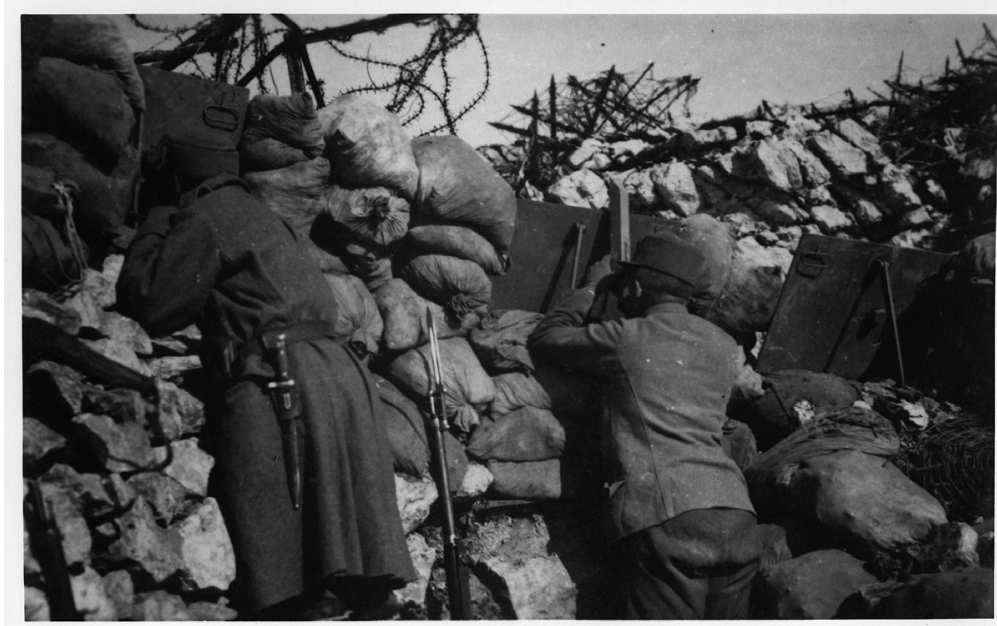

Slika 1: Avstro-ogrska vojska v prvih bojnih linijah na Batognici. Uporabo fotografije je dovolil Muzej novejše zgodovine Slovenije.

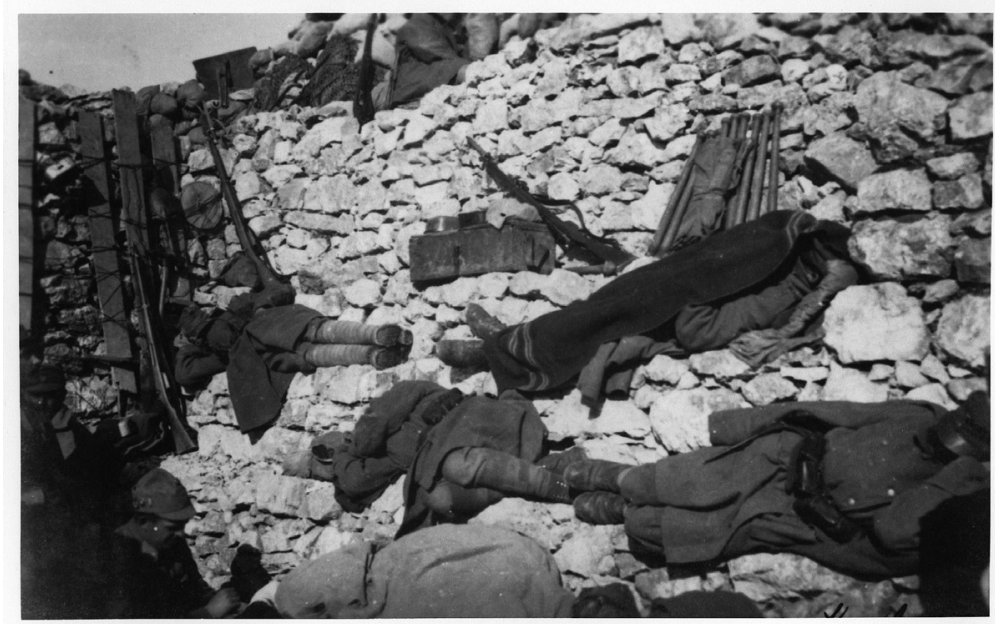

Slika 2: Vojaki med počitkom na fronti na Batognici. Dobro je vidno strelno in hladno orožje, ki so ga uporabljali na fronti. Uporabo fotografije je dovolil Muzej novejše zgodovine Slovenije. 
Neposredno okolje, $v$ katerem so vojaki živeli, se borili in pogosto umirali, je zaznamovalo njihovo dojemanje krajine, izkušenj vojne in spominov ter vzpostavljanje spomenikov in komemorativnih praks po vojni. Med vojno so javnosti vojaško krajino in življenje na frontah reprezentirale zlasti fotografije, filmi, risbe in slike, časopisne poročila, osebni dnevniki, zapisani spomini, romani, vojna poezija in likovna umetnost. »Človeško ceno teh novih krajin so iz dneva v dan opisovali $\mathrm{v}$ spominih in vojnih dnevnikih « (Saunders 2002; 2003). V pripovedih in umetnosti so vojne krajine praviloma prikazovali kot nekaj nezemeljskega, jalovega, pustega, bridkega, brez življenja.

Po vojni je krajina ostala tihi spomin na vojno. Vsebovala je ostanke industrializiranega bojevanja, izkopane jarke, oznake bojišč, materialne ostanke bojev in žrtev. $\mathrm{Na}$ zapuščenih frontah so ostali grobovi neimenovanih vojakov in pogrešanih, postavili so spomenike, nekatera bojišča so se preobrazila $\mathrm{v}$ kraje obiska, vračanja ali romanja. V Franciji so bila nekatera območja tako opustošena, da je bilo zaradi

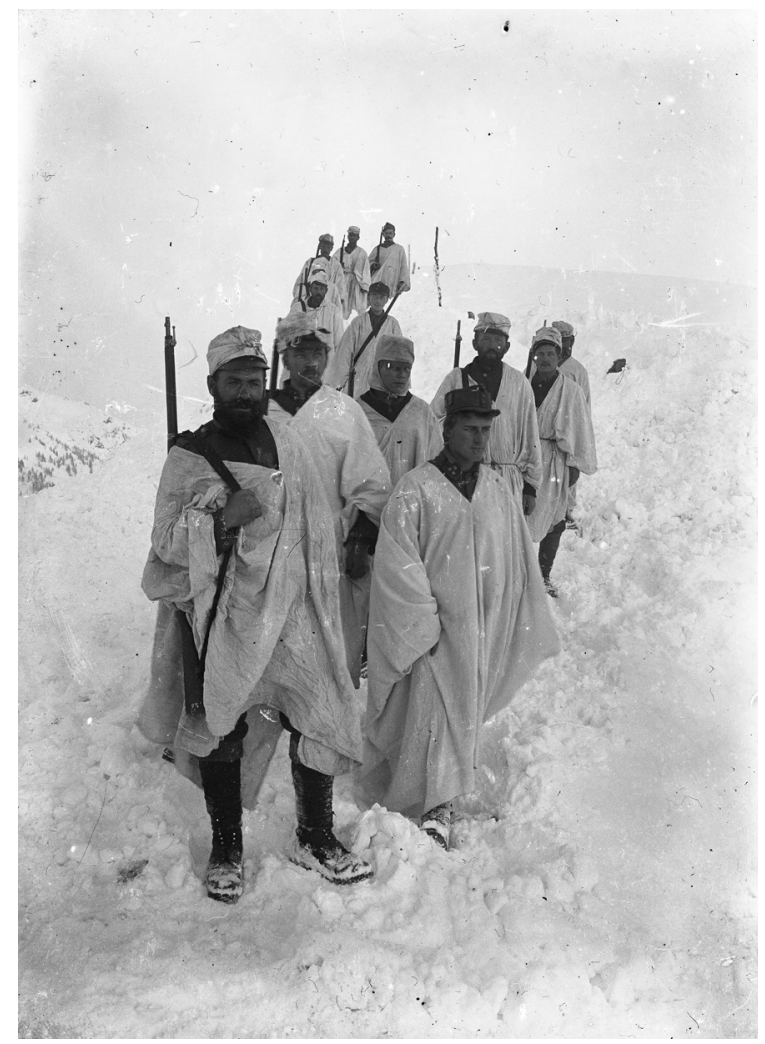

Slika 3: Vojaki so med bojevanjem v zasneženih gorah soške fronte uniforme prekrili z belim kamuflažnim prekrivalom. Uporabo fotografije je dovolil Muzej novejše zgodovine Slovenije. 
ogromnih količin neeksplodiranega streliva prenevarno, da bi jih spet naselili ali začeli obdelovati. Poleg tega so se pojavile tudi napetosti med kmeti, ki so se želeli vrniti na svojo zemljo, in tistimi, ki so želeli, da opustošena zemlja in ruševine ostanejo spominski kraji, hkrati pa trajni opomin vojni in spomeniki žrtvam (glej Saunders 2001a: 41-2). $S$ povojno obnovo ali prepustitvijo propadanju je vojna krajina postala tudi spominska krajina. Vzdolž soške fronte je med vojno v gorah prihajalo do bitk, po vojni pa so domačini zbrali ostanke vojaških artefaktov in sčasoma oblikovali lokalne muzeje in vojaške zbirke, $s$ tem pa tudi reprezentacije vojne (glej Kravanja 2018).

Mnoge vojaške stavbe so podrli ali razstavili, material so pogosto uporabili pri gradnji novih stavb. Nekatere so zgolj opustili ali pa se je spremenila njihova namembnost: stavbe so bile spremenjene $\mathrm{v}$ planinske domove, postavljeni so bili spomeniki in muzeji na prostem. Dele vojaške infrastrukture, kot so poti in žičnice, so še nekaj časa po vojni uporabljali za druge namene. Ozkotirno železniško progo so v Bohinju uporabljali še dve leti po vojni za lokalni prevoz tovora in celo za prevoz turistov. Nekateri kraji, kot so pokopališča in kaverne, so postali spominska obeležja in turistične znamenitosti. Del žičnic med slapom Savica in planoto Komna je bil obnovljen; ta še vedno obratuje kot tovorna žičnica. Nekatere stavbe na planoti Komna so po vojni porušili, druge so še zdaj ohranjene kot planinske koče. Vojno pokopališče na Komni so izkopali, kosti padlih vojakov pa zbrali in postavili spominsko kostnico v obliki piramide. Poti in gorske steze za prevoz topništva in vojakov so po vojni ljudje začeli uporabljati kot pohodniške poti.

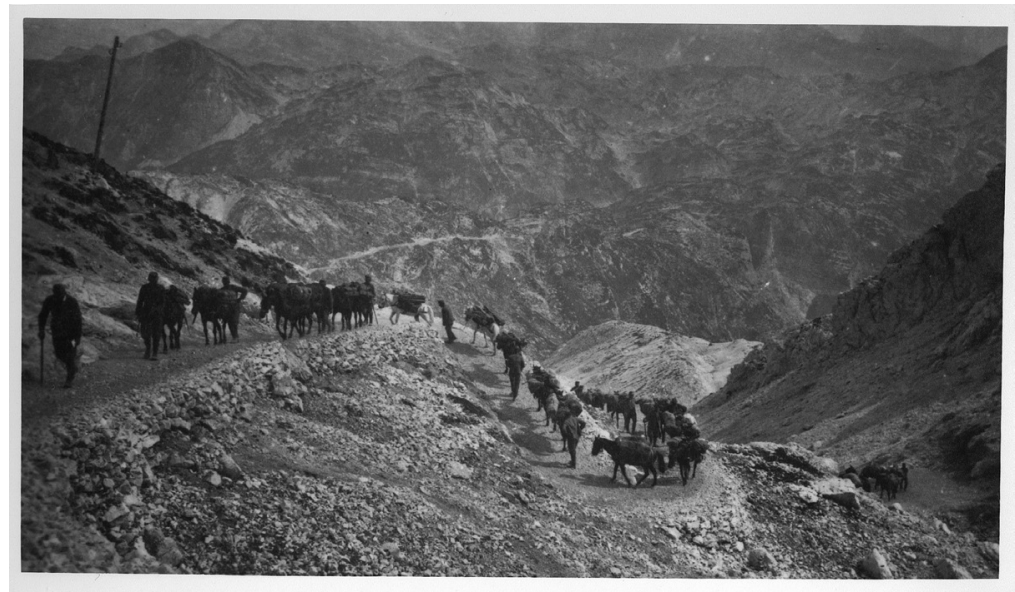

Slika 4: Avstro-ogrski vojaki na poti na fronto v krnskem pogorju. Slika prikazuje pogled s Peskov proti Lemežu in Voglu. Uporabo fotografije je dovolil Muzej novejše zgodovine Slovenije. 


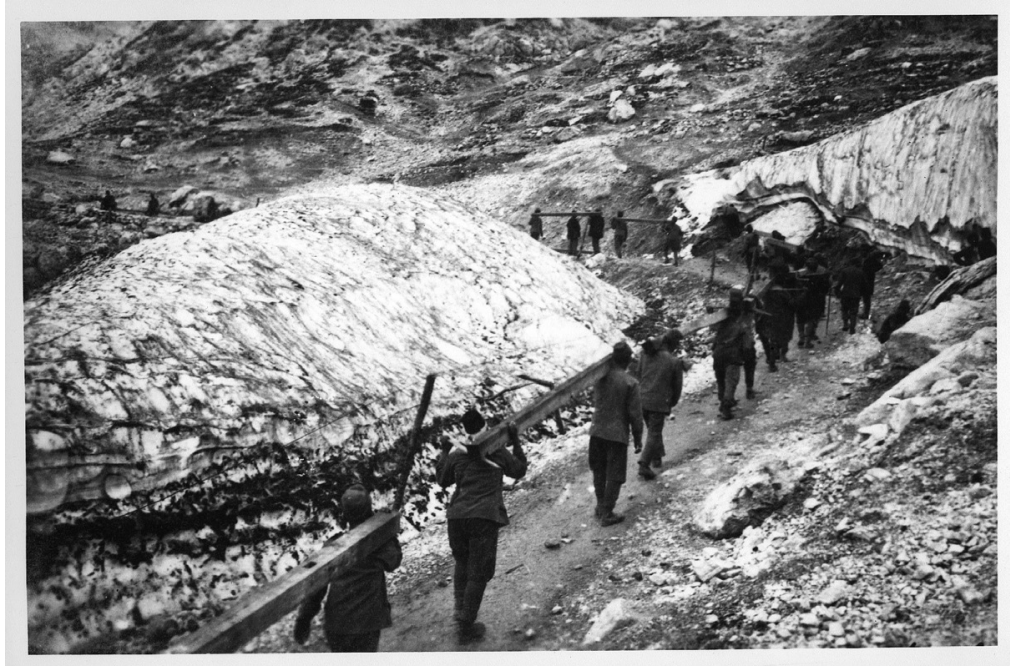

Slika 5: Avstro-ogrska vojska prenaša gradbeni material na planino na Kraju nad Bohinjem, kjer so postavili zadnje vojaško taborišče v zaledju pred fronto. Uporabo fotografije je dovolil Muzej novejše zgodovine Slovenije.

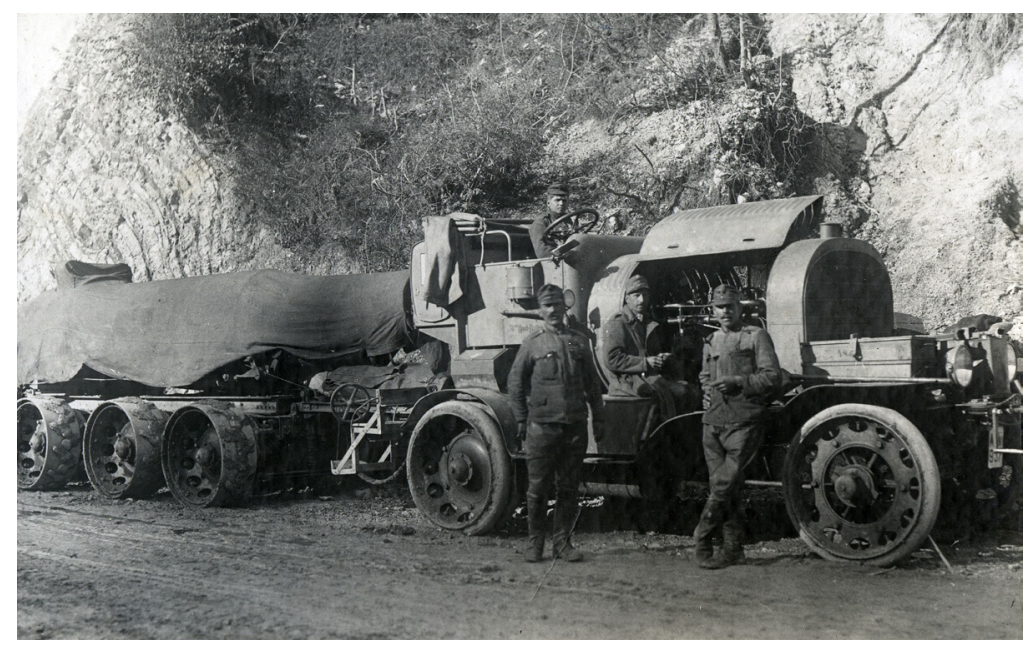

Slika 6: Slika prikazuje prevoz $38 \mathrm{~cm}$ možnarja na cesti v Podbrdo. Pred skupno avstro-ogrsko in nemško ofenzivo so $\mathrm{v}$ Posočje prispeli novi vojaki, pripeljali pa so tudi velike količine orožja ter opreme. Uporabo fotografije je dovolil Muzej novejše zgodovine Slovenije.

$\mathrm{V}$ obdobju med prvo in drugo svetovno vojno so mnogi preživeli ali sorodniki žrtev obiskovali bojišča in vojaška pokopališča. Z drugo svetovno vojno so bile te krajine v veliki meri pozabljene. Kljub nekaterim spomenikom so pokopališča, gorske utrdbe in kapele šele veliko pozneje postali kraji spomina in dediščine, turistični kraji, 
mesta za arheološka raziskovanja ali zbirke vojaških ostankov. Politike in prakse spominjanja in pozabljanja odseva tudi spreminjajoča se vojna oziroma spominska krajina: ostanke bojišč so odstranili, rekonstruirali ali premestili v lokalne muzeje. Saunders opaža, da sta se ponovno odkritje in spominjanje na prvo svetovno vojno v Franciji zares začela šele s petdeseto obletnico vojne (2001a: 45).

Za razliko od Francije v Kraljevini Srbov, Hrvatov in Slovencev umrlih vojakov niso pretirano častili, ker je bilo težko poveličevati vojaški poraz. V Jugoslaviji je bil spomin na prvo svetovno vojno tudi problematičen, ker so se jugoslovanske dežele v njej bojevale na različnih straneh (Jezernik in Fikfak 2018: 14; Jezernik 2018). Poleg tega je bila pomembnejša druga svetovna vojna, ki je bila »konstitutivna za socialistično federativno Jugoslavijo, poleg tega je zmagovita ideologija na vsakem koraku zatrjevala, da sta bratstvo in enotnost, ki ju je skovalo odporniško gibanje, presegla razpoko, ki je med jugoslovanskimi narodi nastala (tudi) med prejšnjo vojno « (Luthar 2000: 97-8; prim. Luthar 2011).

Na območju soške fronte so opazna predvsem številna vojaška pokopališča. Večinoma so na avstro-ogrskem delu postavljali vojaška pokopališča, na italijanski strani pa kostnice. Tudi v Bohinju je bilo postavljenih več spomenikov, posvečenih žrtvam prve svetovne vojne, deloma vojakom avstro-ogrske vojske, pa tudi žrtvam med lokalnimi prebivalci. Med spominskimi kraji sta vojaški pokopališči Rebro v Bohinjski Bistrici in Ukancu. Večina pokopanih je bila vojakov avstro-ogrske vojske, a različnih narodnosti. Med vojno je bilo tudi pokopališče na Planini na Kraju na Komni, ki so ga odstranili nekaj let po vojni. Poleg pokopališč je še nekaj spomenikov: na Planini na Kraju je piramida s spominsko ploščo in vzidanimi kostmi s pokopališča, v Srednji vasi in Koprivniku pa sta spomenika lokalnim žrtvam vojne. Pomembna institucija, ki ohranja in razvija dediščino prve vojne na območju Bohinja, je Muzej Tomaža Godca v Bohinjski Bistrici, ki razstavlja precej bogato zbirko materialnih ostankov vojne, večinoma iz gorskega okolja: uniforme, orožja in strelivo, orodja, prikazuje tudi vojaško bivališče, predstavlja pa tudi življenje med vojno v zaledju in vpetost Bohinja v boje na soški fronti.

Leta 1990 je bil ustanovljen Kobariški muzej, ki predstavlja soško fronto in dediščino prve svetovne vojne. Slovenska vlada je leta 2000 ustanovila Fundacijo Poti miru na območju Soče, katere temeljni namen je ohranjanje dediščine soške fronte. To je preraslo v mednarodni projekt, ki spreminja nekdaj porušene kraje v spominske kraje, soško fronto pa v simbolno krajino spominov in dediščine. Pot miru je spominska pot, ki poteka po slovensko-italijanski meji in povezuje kraje kulturne dediščine prve svetovne vojne med Alpami in Jadranom. Med posebej izpostavljenimi spominskimi kraji na poti so tudi 
Ruska kapelica ob Ruski cesti na Vršič, pokopališče v Logu pod Mangartom, italijanska kostnica v Kobaridu, nemška kostnica v Tolminu, spominska cerkev sv. Duha na Javorci, Sabotin, avstro-ogrsko vojaško pokopališče iz prve svetovne vojne v Solkanu, bohinjska železnica, bohinjski predor ... Na širšem območju so še mnoga druga grobišča, kapele, utrdbe, bojišča, muzeji na prostem in muzeji zasebnih zbirateljev. Pot miru je bila v letu 2016 predložena za vpis na začasni Unescov seznam svetovne dediščine z naslednjo obrazložitvijo:

Prva svetovna vojna je na tem ozemlju pustila trajen pečat. Ob nekdanji fronti je do danes ohranjena bogata materialna dediščina: utrdbe, jarki, opazovalna mesta, transportne poti, koče, naravne in umetne jame, vojaška pokopališča, kostnice, kapele, spomeniki in spominska obeležja.

V obdobju sto let se je spomin na »leta groze « spremenil iz vojaškega $\mathrm{v}$ komemorativnega ter $\mathrm{v}$ skupinsko in nadnacionalno obeleževanje zavoljo spodbujanja miru.

Pot miru po svoji 320 kilometrov dolgi poti povezuje kraje spomina in žalovanja. Prav tako dokazuje trajno človeško moč in si prizadeva za mir, človečnost, osebno dostojanstvo in mednarodno sodelovanje. Pot miru je tako postala krajina spomina ... (UNESCO Tentative Lists)

Čeprav je Bohinj v zaledju soške fronte, se je tudi tam pojavilo nekaj lokalnih spodbud, ki bi Bohinj močneje povezale z dediščino prve svetovne vojne. Med temi so predvsem opazni spominski turizem in muzejske razstave o vojni. Leta 2007 so ustanovili tematsko pot Oskrbovalno zaledje za krnsko bojišče, ki je spominska pohodniška pot po ostankih vojne v dolini in gorah. V planinski koči na Planini na Kraju, ki je del vojaške bolnišnice, so ob stoti obletnici začetka vojne odprli spominsko sobo. Tudi $s$ takšnimi projekti trajno tvorjenje dediščine in komemorativnih praks še vedno spreminjajo interpretacije vojne ter oblikujejo spominsko krajino.

Večji projekti tvorjenja dediščine prve svetovne vojne so se sicer začeli šele v 1990-ih letih in so se razmahnili z vstopom Slovenije v Evropsko unijo. Sploh v času okoli stoletnice vojne so procesi oblikovanja kulturne dediščine prve svetovne vojne še posebej močni (glej Fikfak in Bajuk Senčar 2015; Bajuk Senčar 2018). Nekateri spomeniki so postali tudi kraji turizma, komemorativnih praks in političnih ritualov. »Porast turistov je začel spreminjati tako fizične kot kulturne krajine v smislu novih reprezentacij krajev prve svetovne vojne občinstvu poznega dvajsetega stoletja « (Saunders 2001a: 45).

Med bolj znanimi spominskimi kraji, kjer potekajo tudi komemoracije, bi omenil vsaj še cerkev sv. Duha na Javorci, posvečeno padlim avstro-ogrskim vojakom, ki je leta 2018 dobila znak evropske 
kulturne dediščine kot spomenik posebnega zgodovinskega in kulturnega pomena, in Rusko kapelico ob Ruski cesti na Vršič, posvečeno spominu na žrtve med ruskimi ujetniki, ki so gradili cesto na Vršič.

Za Rusko kapelico, ki so jo postavili vojni ujetniki, so po vojni skrbeli domačini, postala pa je kraj romanj in komemoracij, kar se je končalo z drugo svetovno vojno. Ob kapelici je kostnica, nad njo stoji zidana piramida $\mathrm{z}$ napisom $\gg$ Sinovom Rusije «. Lesena kapelica je sčasoma propadala, po letu 1991 jo je Zavod za varstvo naravne in kulturne dediščine Slovenije deloma obnovil ter zaščitil še grobove ujetnikov. Leta 2006 je bila kapelica popolnoma obnovljena, tudi z donacijami ruskih pokroviteljev. Po letu 1996 so občina Kranjska Gora, Veleposlaništvo Ruske federacije in Društvo Slovenija Rusija obudili spominske slovesnosti. Spominska slovesnost ob Ruski kapelici na dan sv. Vladimirja zadnjo nedeljo v juliju se je uveljavila kot pomemben politično pieteten ritual, na kateri so redno prisotni visoki predstavniki Slovenije in Ruske federacije (Zupanič Slavec in Testen 2007).

\section{PAX}

Prispevek obravnava procese oblikovanja spomina na prvo svetovno vojno in tvorjenja dediščine tako skozi vidik vojne kot povojne spominske krajine. »Pogosto neznosno trpka območja reke Soče na severovzhodu Italije, Ypres Salient v Belgiji ter Somme in Verdun v Franciji so postali glavni primeri socialne konstrukcije krajine [...], ki že od leta 1914 zaznamuje življenja ljudi « (Saunders 2004: 7).

Različne okoljske značilnosti in materialnosti, ki so bile narejene med prvo svetovno vojno ali po njej (poti, utrdbe, jarki, kaverne, pokopališča, spomeniki, ostanki orožja in eksplozivnih sredstev), so danes spomeniki ali spominski kraji, muzejski predmeti, pohodniške poti, turistične znamenitosti ali tematske poti s poudarjeno evropsko konotacijo. Nekatere nastopajo kot zgodovinsko kulturne značilnosti posameznih lokalnosti pri tvorjenju lokalne dediščine ali pri političnih reinterpretacijah prve svetovne vojne (prim. Bajuk Senčar 2018; Kozorog 2018; Kravanja 2018). Ti kraji in materialnosti so konstitutivni del alpske povojne spominske krajine; ostajajo živ spomin na vojno, obenem pa so odprti za nenehne reinterpretacije akterjev, lokalnih in nacionalnih institucij, ki se ukvarjajo z oblikovanjem dediščine.

Vojna in povojna spominska krajina ne zajemata le zgodovinskih plasti iz vojne in različnih povojnih človeških dejavnosti ter naravnega propadanja ali zaraščanja, saj se krajina nenehno spreminja in 
vključuje tako naravne kot arhitekturne tvorbe, poti, ostanke stavb in drugih prostorskih značilnosti, ki so nastale med vojno ali po njej. Po vojni je bila potrebna obnova, ki ni zajemala le stavb in mest, predvsem je bila nujna družbena obnova, pri čemer pomembno vlogo igra tudi ohranjanje spomina nanjo. $\gg V$ tem kontekstu se je temeljito spremenil tudi kolektivni spomin ne le na vzroke in posledice vojne, temveč tudi na njene cilje in smotre « (Jezernik 2014: 334).

Pri Ruski kapelici je bilo 30. julija 2016 obeleževanje stoletnice kapelice in nesreče, ko so vojni ujetniki in drugi umrli v hudem snežnem plazu. Slovesnost je bila letni pietetni dogodek, kjer se udeleženci poklonijo umrlim vojakom in žrtvam prve svetovne vojne. Komemoracija je tudi visok politični ritual, saj je redno prisoten politični vrh Slovenije in Ruske federacije. Na omenjeni slovesnosti sta bila slavnostna govornika predsednik Slovenije Borut Pahor in predsednik Ruske federacije Vladimir Putin. V govorih sta prvo svetovno vojno povezala s sodobnim časom, mednarodnimi odnosi, oba pa sta poudarila prizadevanje za mir. Borut Pahor je prisotne nagovoril z besedami: »Zbrali smo se, ker hočemo trajni mir.«

Pieteta in prizadevanje za mir sta tudi temeljno sporočilo sodobnih projektov, kot je Pot miru, in drugih spomenikov. Na pokopališču v Ukancu lahko preberemo napis: »Potomci: Ostanite si edini, da zaman našo nismo kri prelili.« Ob vhodnih vratih cerkve sv. Duha na Javorci pa je napis Ultra cineres hostium ira non superest (Sovraštvo naj ne sega prek pepela umrlih). Nad vrati na zvoniku, ki ga krasi grb Avstro-ogrske monarhije, pa je napis PAX.

\section{CITIRANE REFERENCE}

ÁrnAson, Arnar 2010 Grief Paves the Way; Karl Benediktsson in Katrín Anna Lund, ur. Conversations with Landscape, str. 79-96. Farnham: Ashgate.

Bajuk Senčar, Tatiana 2005 Kultura turizma: Antropološki pogled na razvoj Bohinja. Ljubljana: Založba ZRC.

2018 From the Hinterland: Commemorating the Centenary of World War I in Bohinj; Folklore: Electronic Journal of Folklore, št. 73, str. 47-66.

BENDER, BARBARA 1993 Introduction: Landscape - Meaning and Action; Barbara Bender, ur. Landscape: Politics and Perspectives, str. 1-17.Oxford: Berg.

2001a Introduction; Barbara Bender in Margot Winer, ur. Contested Landscapes: Movement, Exile and Place, str. 1-18. Oxford: Berg.

2001b Landscapes on-the-Move Journal of Social Archaeology, št. 1, str. 75-89. http://dx.doi.org/10.1177/146960530100100106. 
2002 Time and Landscape.; Current Anthropology, št. 43, str. 103-112. http:// dx.doi.org/10.1086/339561.

Bender, Barbara, In Margot Winer, UR. 2001 Contested Landscapes: Movement, Exile and Place. Oxford: Berg.

Budkovič, Toмaž 1999 Bohinj 1914-1918: Med fronto in zaledjem. Celovec: Mohorjeva družba.

Cosgrove, Denis 1984 Social Formation and Symbolic Landscape. London: Croom Helm.

Cosgrove, Denis in Stephen Daniels, ur. 1988 The Iconography of Landscape. Cambridge: Cambridge University Press.

Cresswell, Tim 2004 Place: A Short Introduction. Oxford: Blackwell.

Daniels, Stephen in Denis Cosgrove 1988 Introduction: Iconography and Landscape; Denis Cosgrove in Stephen Daniels, ur. The Iconography of Landscape, str. 1-10. Cambridge: Cambridge University Press.

Dimitrova, Snezhana 2005 Taming the Death: The Culture of Death (1915-1918) and Its Remembering and Commemorating through First World War Soldier Monuments in Bulgaria (1917-44); Social History, št. 2 str. 175-194. Internetni vir: https://www.tandfonline.com/toc/rshi20/30/2 ?nav=tocList, pregledano 12.9. 2018.

Feld, Steven, in Keith H. Basso 1996 Senses of Place. Santa Fe: School of American Research Press.

FIKfak, JURIJ, IN TATIANA BAJU K SENČAR 2015 Triglavski narodni park: Akterji, strategije, problemi, rešitve; Traditiones, št. 1, str. 7-27. http:// doi.org/10.3986/ Traditio2015440101.

Hirsch, ErIC 1995 Introduction. Landscape: Between Place and Space; Eric Hirsch in Michael O'Hanlon, ur. The Anthropology of Landscape: Perspectives on Place and Space, str. 1-30. Oxford: Clarendon Press.

ILes, Jennifer 2003 Death, Leisure and Landscape: British Tourism to the Western Front; Mark Dorrian in Gillian Rose, ur. Deterritorialisations ... Revisioning Landscapes and Politics, str. 234-243. London: Black Dog Publishing.

Ingold, Tim 1993 The Temporality of the Landscape; World Archaeology, št. 2, str. 152-174. http://dx.doi.org/10.1080/00438243.1993.9980235.

2000 The Perception of the Environment: Essays on Livelihood, Dwelling and Skill. London: Routledge.

INGOLD, Tim IN Jo LeE Vergunst, UR. 2008 Ways of Walking: Ethnography and Practice on Foot. Aldershot: Ashgate.

Jezernik, BožIdAR, In JURIJ FIKFAK, ur. 2018 Cultural Heritage of the Great War; Traditiones, št. 1, str. 7-32.

JEZERNIK, BožIDAR 2014 Mesto brez spomina: Javni spomeniki v Ljubljani. Ljubljana: Modrijan.

2018 Jugoslavija, zemlja snova. Beograd: Biblioteka XX vek. 
Keller, TAit 2009 The Mountains Roar: The Alps during the Great War; Environmental History, št. 2, str. 253-274. http://dx.doi.org/10.1093/ envhis/14.2.253.

Kozorog, Mina 2018 Knowledge of Place in Three Popular Music Representations of the First World War Folklore: Electronic Journal of Folklore, št. 73, str. 76-94.

Kravanja, Boštjan 2018 Learning by Collecting: Amateur Collectors and Their Shifting Positions in Isonzo Front Heritagization and Tourism Adaptation; Folklore: Electronic Journal of Folklore, št. 73, str. 96-116.

Lloyd, David W. 1998 Battlefield Tourism: Pilgrimage and the Commemoration of the Great War in Britain, Australia and Canada, 1919-1939. Oxford: Berg.

Lund, KATrín ANNA, In KARL Benediktsson 2010 Introduction: Starting a Conversation with Landscape; Karl Benediktsson in Katrín Anna Lund, ur. Conversations with Landscape, str. 1-12. Farnham: Ashgate.

LuthaR, Ото 2000 O žalosti niti besede: Uvod v kulturno zgodovino vélike vojne. Ljubljana: Založba ZRC.

$2011 \gg$ Dokler nas smrt ne loči«: Moderna spominska pokrajina in nacionalizacija kolektivnega spomina po prvi svetovni vojni; Tanja Petrović, ur. Politike reprezentacije v Jugovzhodni Evropi na prelomu stoletij, str. 173-199. Ljubljana: Založba ZRC.

Massey, Doreen 2006 Landscape as a Provocation: Reflections on Moving Mountains; Journal of Material Culture, št. 1-2, str. 33-48. Internetni vir: http:// journals.sagepub.com/toc/mcua/11/1-2, pregledano 13.9. 2018.

MorRIS, MANDY S. 1997 Gardens »For Ever England «: Landscape, Identity and the First World War British Cemeteries on the Western Front; Ecumene, št. 4, str. 410-434. Internetni vir: https://www.jstor.org/stable/i40178201, pregledano 13. 9. 2018 .

REPIČ, JAKA 2014 Gibanje kot prostorske prakse in ekonomske strategije na primeru družinskega sirarstva v Bohinju; Ars \& humanitas: Revija za umetnost in bumanistiko / Journal of Arts and Humanities, št. 1, str. 38-57. DOI: 10.4312/ ars.8.1.38-57.

Saunders, Nicholas J. 2001a Matter and Memory in the Landscapes of Conflict: The Western Front 1914-1999; Barbara Bender in Margot Winer, ur. Contested Landscapes: Movement, Exile and Place, str. 37-53. Oxford: Berg.

2001b. Apprehending Memory: Material Culture and War, 1919-1939; John M. Bourne, Peter H. Liddle in Ian R. Whitehead, ur. The Great World War, 1914-1945. Vol. 2: Who Won? Who Lost?, str. 476-488. London: HarperCollins. Internetni vir: http://www.academia.edu/2424285/, pregledano 13. 9.2018.

2002. Excavating Memories: Archaeology and the Great War, 1914-2001; Antiquity, št. 291, str. 101-108. http://dx.doi.org/10.1017/S0003598X00089857.

2003 Trench Art: Materialities and Memories of War. Oxford: Berg.

2004 Material Culture and Conflict: The Great War, 1914-2003; Nicholas J. Saunders, ur. Matters of Conflict: Material Culture, Memory and the First World War, str. 5-25. London: Berg. Internetni vir: http://www.academia. edu/2358286/, pregledano 13. 9. 2018. 
2013 Anthropology and Archaeology of the First World War; Cadernos do CEOM - Patrimônio, Memória e Identidade, št. 38, str. 17-31. Internetni vir: https://bell.unochapeco.edu.br/revistas/index.php/rcc/article/viewFile/1684/927, pregledano 30. 7. 2018.

Petra SvoljŠAK 1997 »Lavina, lavina« ali Rusi gradijo Vršič; Slovenska kronika XX. stoletja, zv. I, str. 174-175. Ljubljana: Nova revija.

Tilley, Christopher 1994 A Phenomenology of Landscape: Places, Paths and Monuments. Oxford: Berg.

2012 'Walking the Past and in the Present; Arnar Árnason, Nicolas Ellison, Jo Vergunst in Andrew Whitehouse, ur. Landscapes Beyond Land: Routes, Aesthetics, Narratives, str. 15-32. New York: Berghahn.

UNESCO Tentative Lists Vir: https://whc.unesco.org/en/tentativelists/6077/, pregledano 12.9. 2018.

Wilson, Ross J. 2011 Tommifying the Western Front, 1914-1918; Journal of Historical Geography, št. 3, str. 338-347. http://dx.doi.org/10.1016/j.jhg.2011.01.001.

Winter, Jay 1998 [1995] Sites of Memory, Sites of Mourning: The Great War in European Cultural History. Cambridge: Cambridge University Press.

2006 Remembering War: The Great War between Memory and History in the Twentieth Century. New Haven: Yale University Press.

WoodwARD, RACHEL 2014 Military Landscapes: Agendas and Approaches for Future Research; Progress in Human Geography, št. 1, str. 40-61. http://dx.doi. org/10.1177/0309132513493219.

Zupanič Slavec, Zvonka, in Petra Testen 2007 Ruska kapelica pod Vršičem. Ob 15-letnici slovensko-ruskih srečanj (1992-2006). Ljubljana: Unireal: Znanstveno društvo za zgodovino zdravstvene kulture Slovenije. 